\title{
Particularities of nailfold capillaroscopy in children - literature review
}

\author{
Sigrid Covaci ${ }^{1,2}$, Oana-Maria Farkas ${ }^{3}$, Alexis-Virgil Cochino ${ }^{1,3}$ \\ ${ }^{1}$ University of Medicine and Pharmacy "Carol Davila", Bucharest, Romania \\ 2"Sf. Maria" University Hospital, Bucharest, Romania \\ ${ }^{3}$ National Institute for Mother and Child Health "Alessandrescu-Rusescu", Bucharest, Romania
}

\begin{abstract}
Nailfold capillaroscopy is a simple, non-invasive and low-cost method, that is extremely important in the assessment of adults and children with definite or suspected connective tissue diseases. Peripheral microvascular changes found in nailfold capillaroscopy examination can provide useful information in differential diagnosis and therapy monitoring in majority of connective tissue diseases. Although in adult rheumatology this method has had an incredibly growing interest in the last decades, studies in paediatric population are fewer and generally, the capillaroscopic data used in children are extrapolated from adults. The normal capillaroscopic pattern in the paediatric population has some differences which must be known when performing nailfold capillaroscopy in children.
\end{abstract}

Keywords: paediatric, nailfold capillaroscopy, connective tissue diseases

\section{INTRODUCTION}

Nailfold capillaroscopy (NFC) is a non-invasive and extremely valuable method used for the study of microcirculation, with clinical applications in the assessment of adults as well as children with definite or suspected connective tissue diseases (CTDs) (1-13).

In adults, the main indication for nailfold capillaroscopy is Raynaud's phenomenon, but in children this condition is rare, and the main indications are represented by CTDs, especially juvenile systemic sclerosis and juvenile dermatomyositis (JDM) (14-21).

Regardless of the patients' age, adults or children, during the examination of nailfold capillaries the following aspects are observed and documented: skin transparency - subpapillary venous plexus; capillary distribution, density, dimensions (width and length), and shape (typical hairpin, tortuous, branched, bushy, dilated or giant capillaries); presence of haemorrhages or oedema and sometimes capillary blood flow $(22,23,24)$.
In children as in adults, a normal nailfold capillaroscopic pattern is represented by a parallel and regular disposition of the distal row, capillaries having with the shape of an open hairpin or reversed $U$ letter, with a thinner arm representing the arterial branch and a thicker arm representing the venous branch, and a density of 7-17 per millimetre, with an average of 9 capillary per millimetre $(6,7,9,12,15,22,23,24)$.

The main particularities in children are represented by a greater visibility of the subpapillary venous plexus, a lower number of capillary loops per millimetre and a higher frequency of atypical capillary loops $(10,12,13,25)$.

\section{Nailfold cappilaroscopy parameters}

The subpapillary venous plexus is visible at birth and becomes progressively invisible with age, so children have a greater visibility of the subpapillary venous plexus compared to adults $(22,24)$. With ageing, when the skin becomes more trans- 
parent, the subpapillary venous plexus may become visible again.

Capillary distribution is a capillaroscopic parameter useful in rheumatology clinical practice. In healthy subjects, whether children or adults, the capillary loops have a homogenous, parallel and ordered distribution, with equal distances between the ascending and descending branches $(6,12,23$, 24,25,26).

Capillary density is defined as the number of capillaries over 1 millimetre found in the distal row of each finger and is one of the most important parameters for early diagnosis of people with an underlying risk for connective tissue diseases $(2,7,23)$. Several studies reported that the capillary density is directly influenced by age, younger children having fewer capillaries compared to older children and adults $(12,27)$. In a study of 70 children (17 of them being healthy children) and 20 healthy adults, linear capillary density was significantly higher in healthy adults (mean 8.6 capillaries $/ \mathrm{mm}$ ) compared with healthy children (mean 6.9 capillaries $/ \mathrm{mm}$ ) (12). This tendency of capillary density to increase with age was reported by many authors as a part of the maturation process $(12,28)$. Considering these differences, some authors developed a capillary density scoring system in which they introduced the age as an effective parameter for quantification of the number of capillaries (27).

Reduced capillary density is defined as $<30$ capillaries per $5 \mathrm{~mm}$ (one nailfold) and avascular area is defined as area where two or more capillaries are missing (6). The scoring systems used for quantification of avascular areas are the same for children as for adults.

Measurement of capillary dimensions includes more parameters but in the daily clinical practice the capillary width and capillary length are the ones usually investigated. There is no consensus regarding the capillary width, different values being reported in the literature. Dolezoleva et al. found a median capillary width of $47 \mu \mathrm{m}$ in healthy children and $40 \mu \mathrm{m}$ in healthy adults, concluding that the capillary width is influenced by age, adults and older children having narrower capillaries compared to younger children (12). In adults, the capillary artery diameter greater than $15 \mu \mathrm{m}$ or that of the venous arm greater than $20 \mu \mathrm{m}$ is classified as dilated capillary $(1,7,23,29)$. Homogeneous widening of the capillaries having a characteristic horseshoe shape and a diameter greater than $50 \mu \mathrm{m}$ $(0.050 \mathrm{~mm})$ are considered giant capillaries (23). Elongated capillaries are defined as capillary loops longer than $300 \mu \mathrm{m}(0.300 \mu \mathrm{mm})(30)$. In current clinical practice, qualitative assessments of the capillary dimensions are considered satisfactory while the semi-quantitative assessments find their usefulness in clinical trials.

Some authors reported that $15-34 \%$ of healthy adults have abnormal capillaries, such as meandering loops, ectasia, bushy loops and bizarre loops $(30,31)$. In the largest paediatric series, the presence of bushy capillaries has been reported in $6 \%$ of healthy children and bizarre capillaries in $27 \%$ of healthy children, the authors considering them as a distinct feature of children's capillary network (25). It seems that children of pre-school age have evenly distributed, wide capillaries, with more tortuous, bizarre shapes, compared with adults (12).

\section{Nailfold capillaroscopy in rheumatic disease}

Of all connective tissue diseases, systemic sclerosis (SSc) has the most specific capillaroscopic pattern and nailfold capillaroscopy is a key investigation in the diagnosis of this disease $(1,8,15)$. Depending on scleroderma microangiopathy'degree and stage, the scleroderma pattern may be characterized by dilated/giant loops, reduced capillary density/avascular areas, meandering loops, haemorrhages and neo-angiogenesis $(1,4,32)$. Capillary abnormalities observed in juvenile and adult SSc are similar $(9,10,34,35)$. Several studies reported the simultaneous presence of giant capillaries and avascular areas in $>60 \%$ of children with juvenile SSc $(10,34,35)$. It is reported that, most children with nonspecific capillary abnormalities at the time of juvenile SSc, develop a scleroderma pattern during the course of the disease. (34).

Approximately $60 \%$ of patients with JDM have a scleroderma pattern $(10,11,35,36)$. In JDM, NFC shows more bushy capillaries compared with juvenile $\operatorname{SSc}(35,36,37)$.

Although a variety of capillaries changes have been reported in $40-90 \%$ of adult and juvenile systemic lupus erythematosus (SLE) cases, no specific pattern has been described $(9,10,12,38)$.

Capillaroscopic changes can also be seen in other paediatric rheumatic diseases but they are less striking than those seen in SSc and JDM.

\section{CONCLUSION}

The normal appearance of nailfold capillaries in children is similar to adults, the differences being represented by a lower number of capillary loops per millimetre, wider capillaries in young children, 
a greater visibility of the subpapillary venous plexus and a higher frequency of atypical capillary loops. These differences should be known and considered in assessing the diagnosis of children with rheumatic diseases, especially CTDs.

Typical capillaroscopic patterns found in CTDs are similar in adult and paediatric population.

Nailfold capillaroscopy is not always easy to perform in children and a mandatory condition is a

\section{REFERENCES}

1. Cutolo M, Sulli A, Pizzorni C, Accardo S. Nailfold videocapillaroscopy assessment of microvascular damage in systemic sclerosis. J Rheumatol 2000; 27: 155-60.

2. Ingegnoli $F$, Gualtierotti R, Lubatti $C$ et al. Feasibility of different capillaroscopic measures for identifying nailfold microvascular alterations. Seminars in Arthritis \& Rheumatism. 2009;38(4):289-295.

3. Le JH, Cho KI. Association between endothelial function and microvascular changes in patients with secondary Raynaud's phenomenon. Clinical Rheumatology. 2014;33(11):1627-1633

4. Maricq HR, Harper FE, Khan MM, Tan EM, LeRoy EC. Microvascular abnormalities as possible predictors of disease subsets in Raynaud phenomenon and early connective tissue disease. Clin Exp Rheumatol. 1983;1(3):195-205.

5. Maricq HR, LeRoy EC. Patterns of finger capillary abnormalities in connective tissue disease by "wide-field" microscopy. Arthritis Rheum 1973; 16: 619-28.

6. Bollinger A, Fagrell B, Clinical capillaroscopy - a guide to its use in clinical research and practice. Hogrefe \& Huber Publishers Toronto 1990: pp. 1-123

7. Cutolo M, Pizzorni C, Sulli A. Capillaroscopy. Best Pract Res Clin Rheumatol. 2005; 19( 3): 437-52.

8. Cutolo M, Sulli A, Secchi ME, Olivieri M, Pizzorni C. The contribution of capillaroscopy to the differential diagnosis of connective autoimmune diseases. Best Pract Res Clin Rheumatol. 2007;21(6): 1093-108.

9. Ingegnoli F, Herrick AL (2013). Nailfold Capillaroscopy in Pediatrics. Arthritis Care \& Research, 65: 1393-1400. doi:10.1002/acr.22026

10. Spencer Green G, Schlesinger M, Bove KE, Levinson JE, Schaller JG, Hanson V et al. Nailfold capillary abnormalities in childhood rheumatic diseases. J Pediatr 1983;102:341-6.

11. Carpentier $P$, Jeannoel $P$, Bost $M$, Franco A. Peri-ungual capillaroscopy in pediatric practice. Pediatrie 1988;43(2):165-9.

12. Dolezalova P, Young SP, Bacon PA, Southwood TR. Nailfold capillary microscopy in healthy children and in childhood rheumatic diseases: a prospective single blind observational study. Annals of the Rheumatic Diseases. 2003;62(5):444-449. doi: 10.1136/ard.62.5.444.

13. Piotto DG, Len CA, Hilario MO, Terreri MT. Nailfold capillaroscopy in children and adolescents with rheumatic diseases. Rev Bras Reumatol. 2012;52:722-32.

14. Cutolo M, Grassi W, Matucci Cerinic M. Raynaud's phenomenon and the role of capillaroscopy. Arthritis Rheum. 2003;48(11):3023-30

15. Cutolo M, Pizzorni C, Tuccio M et al. Nailfold videocapillaroscopy patterns and serum autoantibodies in systemic sclerosis, Rheumatol 2004, 43: 719-726

16. Belch JJF. Raynaud'phenomenon: its relevance to scleroderma. Ann Rheum Dis. 1991;50:839-45.

17. Block JA, Sequeira W. Raynaud's phenomenon. Seminar Lancet, 357 2001, 2042-8.

18. Krieger I, Brough AJ. Raynaud's phenomenon in an infant. J Pediatr. 1972;80:145-51.

19. Herrick AL, Jayson MI. Primary Raynaud's phenomenon in early childhood. Br J Rheumatol. 1991;30:223-5.

20. Guntheroth WG, Morgan BC, Harbinson JA, Mullins GL. Raynaud's disease in children. Circulation. 1967;36:724-9. good collaboration with the patient. Paediatric patients may need prolonged accommodation time and more reassuring regarding the pain free procedure.

NFC is a feasible examination in children because it is a simple, non-invasive, low-cost, easy to perform and easy to repeat procedure, being also the best method for microangiopathy evaluation.

Conflict of interest: none declared Financial support: none declared

21. Nigrovic PA, Fuhlbrigge RC, Sundel RP. Raynaud's phenomenon in children: A retrospective review of 123 patients. Pediatrics. 2003;111:715-21.

22. Etehad Tavakol M, Fatemi A, Karbalaie A, Emrani Z, Erlandsson BE. Nailfold Capillaroscopy in Rheumatic Diseases: Which Parameters Should Be Evaluated? Biomed Res Int. 2015;2015:974530.

23. Cutolo M., Sulli A., Smith V. How to perform and interpret capillaroscopy. Best Practice and Research: Clinical Rheumatology. 2013 Apr; 27(2):237-248.

24. Allen J. Capillaroscopy in Healthy Subjects of Different Ages. In: Cutolo M, editor. Atlas of Capillaroscopy in Rheumatic Diseases. Milan: Elsevier; 2010. pp. 49-53.

25. Terreri MT, Andrade LE, Puccinelli ML, Hilário MO, Goldenberg J. Nail fold capillaroscopy: Normal findings in children and adolescents. Semin Arthritis Rheum. 1999 Aug;29(1):36-42

26. Kamińska-Winciorek A., Deja G., Polańska J., Jarosz-Chobot P. Diabetic microangiopathy in capillaroscopic examination of juveniles with diabetes type 1. Postępy Higieny i Medycyny Doświadczalnej. 2012; 66:51-59.

27. Hoerth C., Kundi M., Katzenschlager R., Hirschl M. Qualitative and quantitative assessment of nailfold capillaries by capillaroscopy in healthy volunteers. Vasa. 2012;41(1):19-26. doi: 10.1024/0301-1526/ a000159.

28. Herrick AL, Moore T, Hollis S, Jayson MIV. The influence of age on nailfold capillary dimensions in childhood. J Rheumatol. 2000; 27:797-800.

29. Herrick AL, Clark S. Quantifying digital vascular disease in patients with primary Raynaud's phenomenon and systemic sclerosis. Ann Reum Dis. 57, 1998, 70-78

30. Kabasakal Y, Elvins DM, Ring EFJ, McHugh NJ. Quantitative nailfold capillaroscopy findings in a population with connective tissue disease and in normal healthy controls. Ann Rheum Dis 1996;55:507-12.

31. Andrade LEC, Gabriel A Jr, Assad RL, Ferrari AJL, Atra E. Panoramic nailfold capillaroscopy: A new reading method and normal range. Semin Arthritis Rheum 1990;20:21-31.

32. Maricq HR, Widefield capillary microscopy. Technique and rating scale for abnormalities seen in scleroderma and related disorders, Arthr Rheum 1981, 24: 1159-1165

33. Martini G, Foeldvari I, Russo R, Cuttica R, Eberhard A, Ravelli A et al. Systemic sclerosis in childhood: clinical and immunologic features of 153 patients in an international database. Arthritis Rheum 2006; 54:3971-8.

34. Russo R, Katsicas M. Clinical characteristics of children with juvenile systemic sclerosis: Follow up of 23 patients in a single tertiary center. Pediatr Rheumatol 2007;5:1-9.

35. Nussbaum Al, Silver RM, Maricq HR. Serial changes in nailfold capillary morphology in childhood dermatomyositis. Arthritis Rheum. 1983; 26:1169-72.

36. Silver RM, Maricq HR. Childhood dermatomyositis: serial microvascular studies. Pediatrics. 1989;83:278-83.

37. Smith RL, Sundberg J, Shamiyah E, Dyer A, Pachman LM. Skin involvement in juvenile dermatomyositis is associated with loss of end row nailfold capillary loops. J Rheumatol 2004;31(8):1644-9.

38. Redisch W, Messina EJ, Hughes G, McEwen C. Capillaroscopic observations in rheumatic diseases. Ann Rheum Dis. 1970;29:244-53 